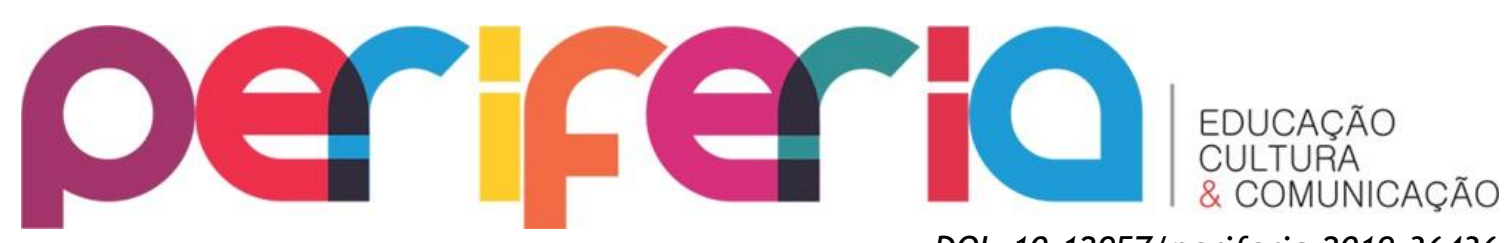

DOI: $10.12957 /$ periferia.2019.36436

\title{
LEITURA LITERÁRIA E MEMES: ANÁLISE DE UMA PROPOSTA
}

\author{
Katrym Aline Bordinhão dos Santos ${ }^{1}$ \\ Instituto Federal do Paraná - Campus Telêmaco Borba
}

\section{Resumo}

Aliar novas tecnologias ao ensino de literatura esbarra no desafio de não se deixar o texto literário em segundo plano ou apenas mudar o suporte em que ele aparece, sem que haja, de fato, uma preocupação com sua interpretação. Com o objetivo de refletir sobre uma proposta acerca da compreensão de um texto literário, este trabalho apresenta uma experiência realizada em sala de aula com turmas do ensino médio e a leitura dos textos $\mathrm{O}$ alienista, de Machado de Assis, e A hora da estrela, de Clarice Lispector, demonstrando uma prática de uso do texto literário vinculada à criação de memes, que também podem ser considerados gêneros textuais. Levando em conta os apontamentos de Rildo Cosson e Jean Foucambert, discute-se a validade e os resultados da atividade, que aborda um gênero que é de conhecimento dos estudantes e que gera até mesmo estranheza quando é aproximado da prática da aula de literatura. Notadamente se percebeu o interesse de uma parcela dos estudantes, acostumados com o gênero textual, o que culminou na produção de memes que demonstraram um repertório criativo na busca por atingir o sentido que experimentaram nas leituras. Em suma, verificou-se uma apropriação do sentido e das diversas possibilidades de se abordar um fato que pode soar aparentemente sem importância no enredo, mas que, fazendo parte da literatura, permite reflexões sobre o processo de formação humana propiciado por essa tarefa, potencializada pela escola, espaço do qual se espera tal experiência.

Palavras-chave: literatura; leitura; memes

${ }^{1}$ Doutora em Letras - Literatura, trabalha com língua portuguesa e literatura no ensino médio técnico integrado e ensino superior. katrym.santos@ifpr.edu.br 


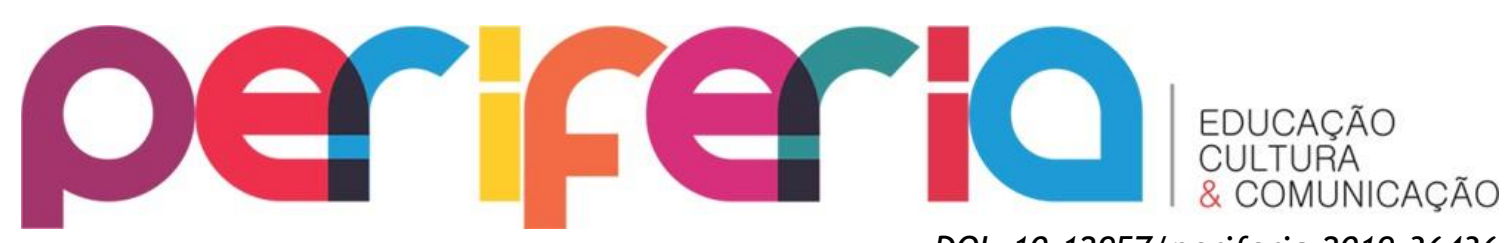

DOI: $10.12957 /$ periferia.2019.36436

\title{
LITERARY READING AND MEMES: ANALYSIS OF A PROPOSAL
}

\begin{abstract}
Allying new technologies with literature teaching faces the challenge of not letting the literary text fall into the background or just change the medium in which it appears, with no real concern for its interpretation. Aiming to reflect on an suggestion about the understanding of a literary text, this work presents an experiment in class with high school classes and the reading of the texts The Alienist by Machado de Assis and The Hour of the Star by Clarice Lispector, demonstrating a practice of using the literary text linked to the creation of memes, which can also be considered textual genres. Taking into account the notes of Rildo Cosson and Jean Foucambert, it discusses the validity and results of the activity, which addresses a genre that is known to the students and which generates even strangeness when it is approached to the practice of literature class. Notably it was realized the interest of a portion of students, accustomed to the genre, which culminated in the production of memes that have demonstrated a creative repertoire in the quest for achieving the sense that experienced in the readings. In short, an appropriation of the meaning and the different possibilities of approaching a fact that may seem seemingly unimportant in the plot, but which, being part of the literature, allows reflections about the process of human formation propitiated by this task, potentialized the school, space which is expected such an experience.
\end{abstract}

Keywords: literature; reading; memes 


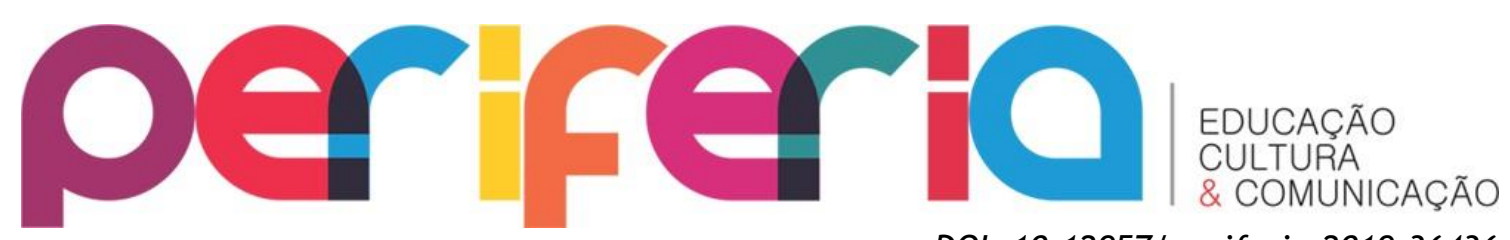

DOI: $10.12957 /$ periferia.2019.36436

\section{LA LECTURA LITERARIA Y LOS MEMES: ANÁLISIS DE UNA PROPUESTA}

\section{Resumen}

Aliar las nuevas tecnologías a la enseñanza de literatura se tropieza al reto de no dejar el texto literario en segundo plano o solamente cambiar el soporte en que él se muestra, sin que haya, de hecho, una preocupación con su interpretación. Con el objetivo de reflejar sobre una metodología acerca de la comprensión de un texto literario, esta investigación presenta una experiencia realizada en aula con grupos de la secundaria y la lectura de dos textos 0 Alienista, de Machado de Assis, y A hora da estrela, de Clarice Lispector, demostrando una práctica de uso del texto literario entrelazada a la creación de memes, que también pueden ser considerados géneros textuales. Teniendo en cuenta los apuntes de Rildo Cosson y Jean Foucambert, se discute la validad y los resultados de la actividad que aborda un género que es de conocimiento de los estudiantes y que genera, incluso, una rareza cuando se lo aproxima de la práctica de la clase de literatura. Notablemente se ve el interés de una parte de los estudiantes, acostumbrados con el género textual, lo que ha culminado en la producción de memes que demuestran un directorio creativo en la busca por alcanzar el sentido que experimentaron en las literaturas. En suma, se observa una apropiación del sentido y de las diversas posibilidades de abordarse un facto que puede sonar aparentemente sin importancia en el enredo, pero, que, formando parte de la literatura, permite reflexiones sobre el proceso de formación humana propiciado por esa tarea, potenciada por la escuela, espacio lo cual se espera tal experiencia.

Palabras clave: literatura, lectura, memes 


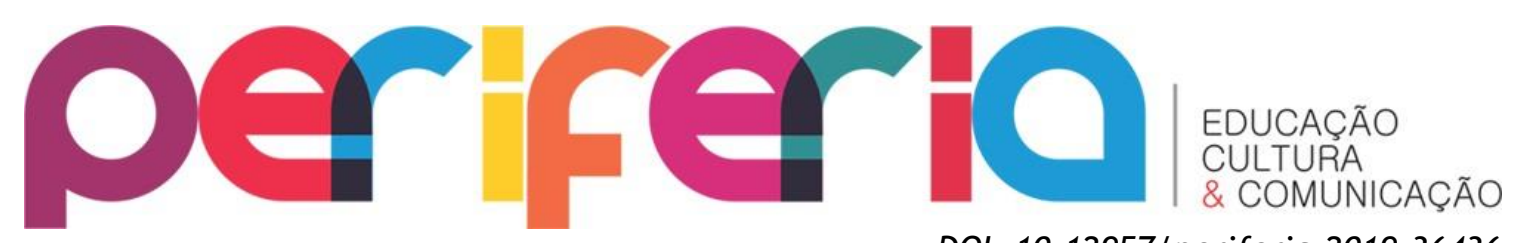

INTRODUÇÃO

DOI: $10.12957 /$ periferia.2019.36436

É notável no cotidiano escolar como os estudantes sentem-se identificados quando os professores fazem comentários acerca de fatos que eles conhecem, principalmente no que diz respeito às redes sociais. O Facebook, Twitter, entre outros, são as redes em que eles, muitas vezes, buscam contato ou procuram o perfil do próprio professor, como que para humanizar aquela figura presente na sua vida escolar.

Alguns professores, naturalmente, também são usuários dessas redes, e é nelas que muitas vezes encontram material de apoio para pensar em suas aulas e formas de se aproximar daquilo que os seus estudantes vivenciam. Como sabemos, a escola muitas vezes é incriminada de ensinar conteúdos nos quais os estudantes não visualizam aplicação, fazendo com que não tenham interesse em saber algo que "não vão usar". Dessa forma, familiarizar-se com o mundo virtual experimentado por eles surge como uma saída para esse cenário. Justamente numa situação de uso pessoal dessas redes é que encontramos a matéria jornalística que deu origem à proposta aplicada em sala de aula e que será aqui apresentada, a criação de memes acerca de livros literários.

A notícia do jornal El País ("A professora que pediu a suas alunas 'memes' de 'Cem Anos de Solidão'”, de Gloria Rodriguez Pina) relatava o caso de uma professora chilena que pediu a suas alunas que criassem memes a respeito da leitura do romance Cem anos de solidão, de Gabriel Garcia Marquez. 0 texto relata que a professora se preocupou em pedir um tipo de avaliação que fosse diferenciado, para que eles não ficassem apenas respondendo perguntas, pois ela acredita que os alunos atuais não querem mais ficar somente sentados, ouvindo e respondendo provas.

Sabemos da importância dessa escuta e resposta de questões, e em uma situação de aula de língua materna isso é ainda mais claro, dada a necessidade de se promover momentos de escrita, por exemplo. Ainda assim, a preocupação da professora é legítima e os resultados apresentados na matéria do jornal demonstravam uma oportunidade interessante de se pensar uma abordagem de leitura de texto literário. 


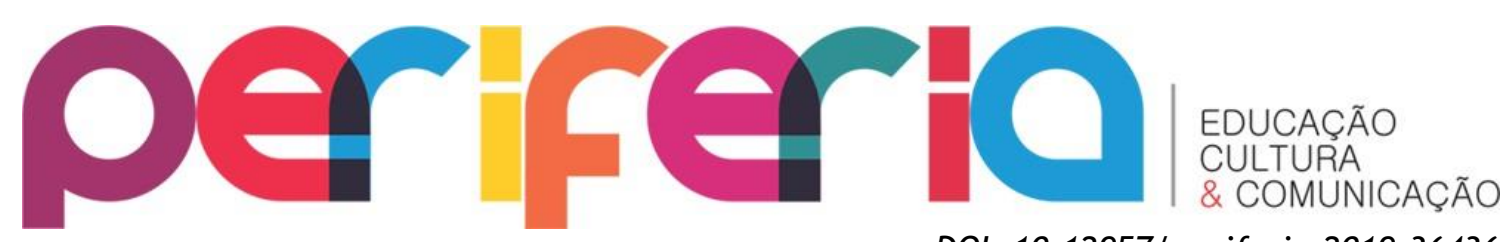

DOI: $10.12957 /$ periferia.2019.36436

Os exemplos de memes produzidos e apresentados na matéria permitiam que se notasse o potencial de interpretação que essa tarefa poderia promover, além das colocações da professora sobre esse processo: “'Ao fazer essa atividade elas precisavam captar a essência de determinados momentos da narração. Sem dúvida, o lúdico foi muito bom para conseguir que a leitura fosse significativa'” (PINA, 2016). Note-se como a interpretação necessária é o ponto chave dessa avaliação, uma vez que o estudante precisa compreender o que leu e ainda criar algo que permita ao leitor um entendimento esperado por ele.

A preocupação em utilizar a tecnologia no ensino da literatura sem que isso vire um expediente para que se afaste do texto propriamente dito é sempre um perigo que ronda novas propostas, a nosso ver. Ler acaba ficando em segundo plano e analisar a questão teórica do texto literário acaba nem sendo feito. Com isso, atesta-se o senso comum de a literatura existir apenas como um hobby. Essa experiência com o uso dos memes nos parece diferente justamente porque para que a produção faça sentido é preciso que o entendimento do texto tenha ocorrido e que se crie um novo que seja passível de compreensão pelo leitor do texto literário também, o que, portanto, não diminui sua importância.

Além disso, um trabalho introdutório à atividade que explore as questões de narração poderá esclarecer os meandros do texto, colaborando na tarefa da interpretação, para que a produção que será realizada depois não culmine na abordagem apenas de aspectos superficiais de enredo, por exemplo. Questões como foco narrativo, caracterização de personagens, ambiente e trabalho com o tempo são primárias e facilmente abordáveis nesse tipo de atividade.

Ainda de acordo com a publicação:

Os memes foram compartilhados mais de 11.000 vezes desde sua publicação, em 7 de junho. A professora foi entrevistada pela $\mathrm{BBC}$ em espanhol e por outros meios de comunicação do Chile - e também da Colômbia, da Venezuela, do Peru, da Bolívia, da Argentina e da Espanha. "Foi caótico e impactante para mim", conta para este jornal. Bustamante comemora que sua iniciativa tenha servido para inspirar outros educadores e que surja o desejo de inovar na educação: "Talvez tenha aberto o caminho para que mais educadores no mundo usem as redes de forma positiva em suas aulas e fora delas". 


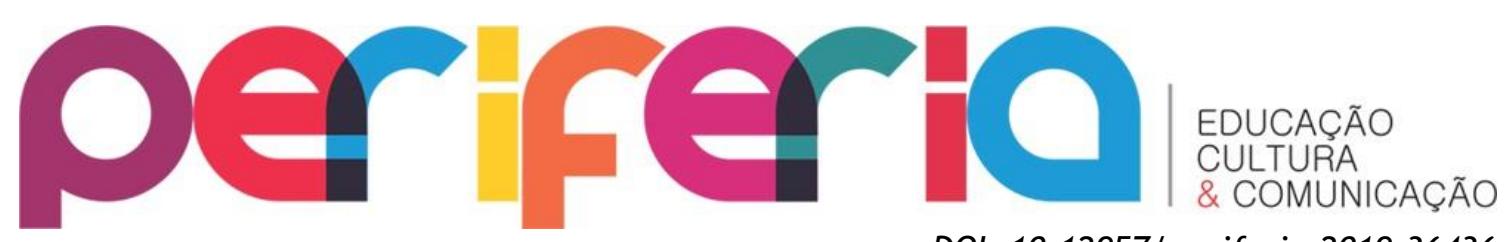

DOI: $10.12957 /$ periferia.2019.36436

O número de compartilhamentos impressiona, mas não é um critério aqui levado em conta para a experiência que nos propusemos a repetir. A grande questão é a última fala da professora, sobre usar as redes em sala com o intuito de tornar as aulas mais próximas da realidade dos alunos. Quando ela menciona o caminho para outros educadores notamos a importância que a troca de informações entre os pares pode gerar para que tenhamos experiências de qualidade no cotidiano escolar.

Neste artigo apresentaremos a experiência de atividade envolvendo leitura literária e tecnologia nas aulas de língua portuguesa e literatura em turma do ensino médio. Levando em conta os apontamentos de Rildo Cosson (2012) e Jean Foucambert (2008), discute-se a validade e os resultados da atividade, que aborda um gênero que é de conhecimento dos estudantes e que gera até mesmo estranheza quando é aproximado da prática da aula de literatura.

\section{A PROPOSTA NO IFPR - CAMPUS TELÊMACO BORBA}

Inicialmente é importante pontuar a importância de se utilizar uma proposta que aborda um gênero textual vivenciado pelos estudantes e que, portanto, se mostra como aplicável na rotina deles, o que, a nosso ver, os instiga a compreender e produzir as atividades relacionadas.. 0 contato com os gêneros textuais é reiterado pelos diversos documentos norteadores do ensino de língua materna, tendo em vista que são a concretização das realidades de uso da língua. Logo, é preciso esclarecer o conceito que assumimos nesta ocasião. De acordo com Mikhail Bakhtin (2003, p. 279):

Qualquer enunciado considerado isoladamente é, claro, individual, mas cada esfera de utilização da língua elabora seus tipos relativamente estáveis de enunciados, sendo isso que denominamos gêneros do discurso. A riqueza e a variedade dos gêneros do discurso são infinitas, pois a variedade virtual da atividade humana é inesgotável, e cada esfera dessa atividade comporta um repertório de gêneros do discurso que vai diferenciando-se e ampliando-se à medida que a própria esfera se desenvolve e fica mais complexa. 


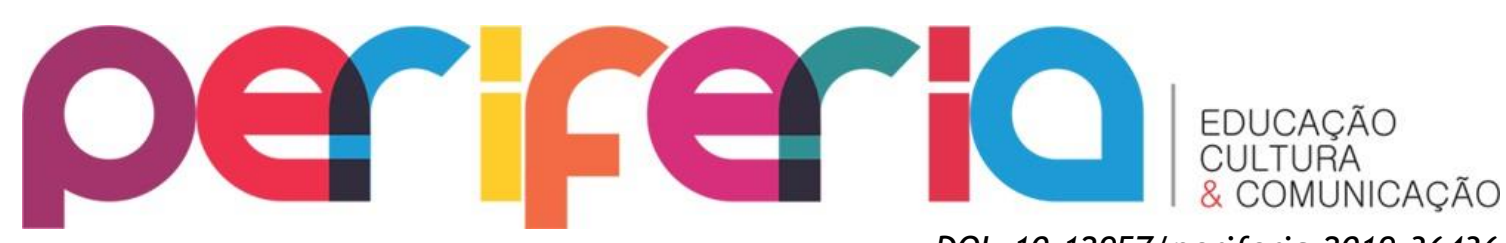

DOI: $10.12957 /$ periferia.2019.36436

Note-se como a menção à variedade de gêneros nos coloca diante do desafio que se apresenta quando nos propomos a abordá-los em sala de aula, ainda mais considerando a rapidez com que novas demandas comunicativas surgem. Para considerarmos o meme como gênero textual nos baseamos no artigo de Ananias Agostinho da Silva (2016) "Memes virtuais: gênero do discurso, dialogismo, polifonia e heterogeneidade enunciativa", no qual o autor define esse elemento e pontua que "Defendemos, aqui, que o meme virtual é, pois, um gênero do discurso justamente porque, assim como os demais gêneros, nasce no interior de práticas discursivas de interação humana e apresenta conteúdo temático, estilo e estrutura composicional." (SILVA, 2016, p.348). Assim, passamos a entender que, de fato, o meme pode ser um dos gêneros textuais que comumente abordamos nas aulas de produção de texto.

De forma mais detalhada, o autor ainda lança mão de outros estudos que explicam o entendimento do meme como um texto:

Souza (2013), acertadamente, justifica o emprego da
nomenclatura textos mêmicos: os memes são textos porque
atuam como meio de comunicação e transmissão de
conhecimento e são mêmicos porque são passados de indivíduo
para indivíduo em ambiente virtual por questões de filiação e
adesão aos sentidos construídos pelo conteúdo expresso. Se
retomarmos o conceito de texto de Koch (2003, p. 22), no
âmbito da Linguística do Texto desenvolvida no Brasil, qual
seja, "atividade verbal de indivíduos socialmente atuantes, na
qual estes coordenam suas ações no intuito de alcançar um fim
social, em conformidade com as condições sob as quais a
atividade verbal se realiza", veremos que os memes podem ser
considerados como textos porque são manifestações verbais
que permitem aos usuários interagirem, a partir da depreensão
de elementos semânticos e de estratégias cognitivas, em uma
dada situação sociocultural. (2016, p.348)

Diante do nosso objetivo, quando da aplicação da atividade aqui descrita e mesmo na reflexão apresentada nesta oportunidade, era justamente a organização e escolha dessas estratégias de significado buscando um efeito sociocultural que pautava a aposta na abordagem. Ao selecionar as imagens que girarão em torno do meme a ser produzido, o ou a estudante posiciona-se e faz uma interpretação do momento vivido tanto na ocasião da produção quando no tempo abordado na produção literária em questão. A relação da aula com a 


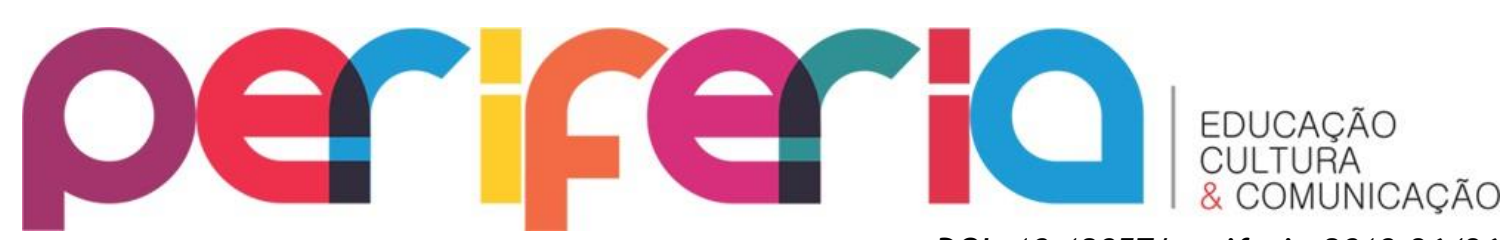

DOI: $10.12957 /$ periferia.2019.36436 realidade, mais uma vez, surge em meio à rotina escolar, um de nossos objetivos.

Cientes, então, da viabilidade teórica dessa proposta, optamos por realizar essa atividade, a saber, a criação de memes que abordassem aspectos que os estudantes mais acharam interessantes nos textos literários, no campus Telêmaco Borba do IFPR - Instituto Federal do Paraná, com turmas do segundo e terceiros anos do ensino médio integrado dos cursos de Automação Industrial, Informática para Internet e Mecânica, nos anos de 2016 e 2017, totalizando 180 estudantes.

Os textos escolhidos foram $O$ alienista, de Machado de Assis, e $A$ hora da estrela, de Clarice Lispector, respectivamente. Tais escolhas se basearam nos autores previstos para serem lidos nas séries, e para fugirmos da perigosa leitura de trechos descontextualizados. Assim, a realização da atividade ocorreu após um mês de discussões sobre as obras, tanto no que diz respeito à enredo quanto à teoria literária. A primeira ação foi apresentar aos estudantes a matéria que explicava o trabalho da professora chilena, para que eles entendessem que se tratava de uma experiência que partiu do uso efetivo de uma rede social e de como os professores preocupam-se com metodologias de ensino antes de propor atividades em sala. Quase como uma experiência de metalinguagem, o intento é fazer, também, com que valorizem as aulas e a figura do professor, compreendendo que há uma preparação por detrás do que lhes é proposto.

Nesse processo, considerando a realidade em que os alunos estão inseridos, Paula Minhoto e Manuel Merinhos (2011, p.25) sugerem que, "a instituição de ensino pode tirar proveito do interesse dos alunos pelas redes sociais e articular com os objetivos pedagógicos escolares, com isso conseguir que eles desenvolvam as competências previstas pelos programas das disciplinas”. Assim, aliar o interesse dos alunos em memes com a promoção da capacidade de criar um texto com objetivos claros é um dos escopos do ensino de língua portuguesa e literatura, exemplificando o que os autores mencionaram. 


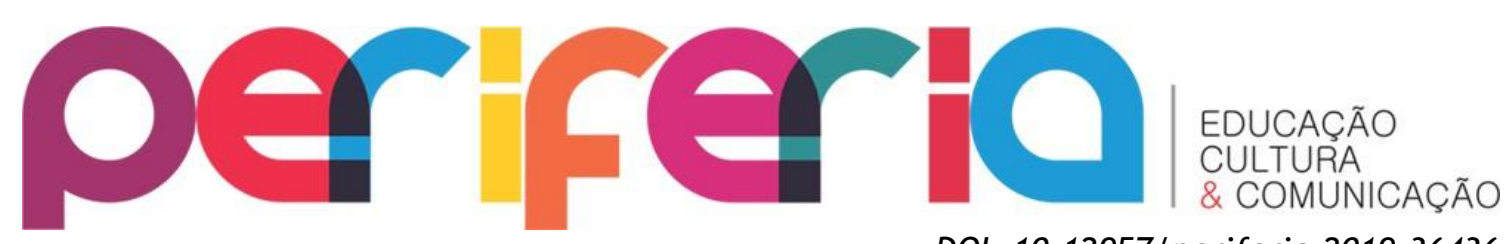

DOI: $10.12957 /$ periferia.2019.36436

Ao mesmo tempo, essa contextualização do universo escolar com o pessoal do aluno, para Costa e Vilaça (2013, p. 817), "tem como finalidade permitir que a escola seja capaz de estender seu espaço para além de seus muros e cativar interesse de seus estudantes". Produzir conhecimento que ficará preso entre os muros da instituição de ensino é inócuo, de modo que mostrar ao aluno ou a aluna que há um espaço lá fora em que é preciso ter voz, e que a escola pode colaborar nisso, torna-se uma justificativa para atividades desse caráter.

A proposta, inicialmente, causou estranhamento nos estudantes por conta de seu caráter pouco formal, já que estão acostumados a produzir textos que parecem ter uma função prática mais claramente delineada. Como se costuma fazer em momentos de escrita, definimos o que configura um meme da seguinte forma, utilizando Ananias Silva (2016, p. 342) mais uma vez:

Os memes podem ser formados por imagens, por figuras, fotografias, frases, palavras-chaves ou qualquer outro elemento que apresente um conteúdo irônico ou humorístico que se propague ou se replique na rede. Surgem, replicam-se e transformam-se na rede em uma velocidade impressionante, o que nos permite compará-los a um vírus que se espalha de forma epidêmica, contaminando um número impressionante de pessoas.

Mesmo que eles já soubessem o que configura um meme, até melhor do que a própria professora, essa descrição, aliada à exibição dos exemplos constantes na matéria de jornal e a possibilidade de saírem da tensão de uma prova escrita, parece ter criado um interesse que acabou demonstrado nas produções apresentadas. Durante a realização da atividade os comentários em torno do que poderia servir de material para o meme também revelava as inúmeras visões acerca de um mesmo evento ou personagem, tornando a tarefa extremamente produtiva.

Diante do domínio do local de circulação do gênero textual pelos estudantes, é preciso admitir que foram encontradas dificuldades na compreensão de determinados resultados por parte da professora, haja vista a exposição a esse tipo de produção, que, obviamente, é diversa da vivida por 


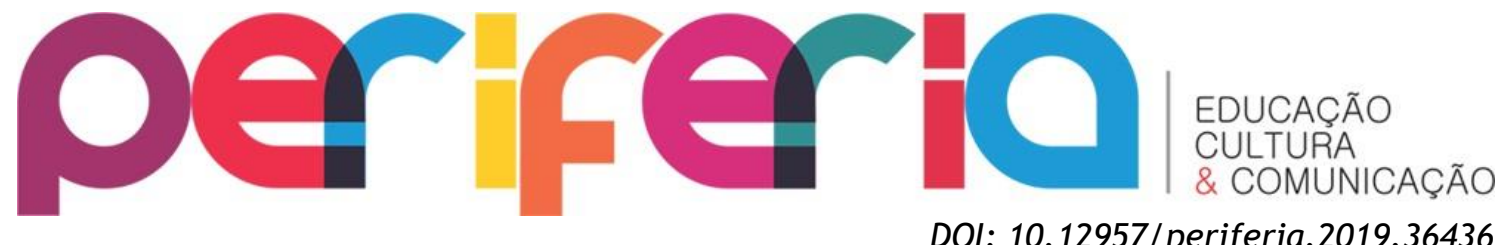

adolescentes. Isso também serviu como assunto da aula, considerando que é importante que eles visualizem a figura da professora como alguém que também pode ter dúvidas e interpretar de formas diferenciadas algo que para quem produziu o texto parece tão óbvio. Tal experiência serviu para que refletissem sobre os pormenores da linguagem escrita.

A seguir analisamos dois memes que nos parecem representar o caráter marcante da opção semântica, calcada pela influência do momento vivido pelas alunas e alunos. 0 critério de escolha também levou em conta a abordagem dos dois livros mencionados como enfoque e a relação com elementos de destaque no momento da produção, já que ambos os selecionados datam de 2016. 0 primeiro aborda a história de Macabéa, e foi produzido por alunas do terceiro ano do curso médio intregrado ao técnico em Automação Industrial:

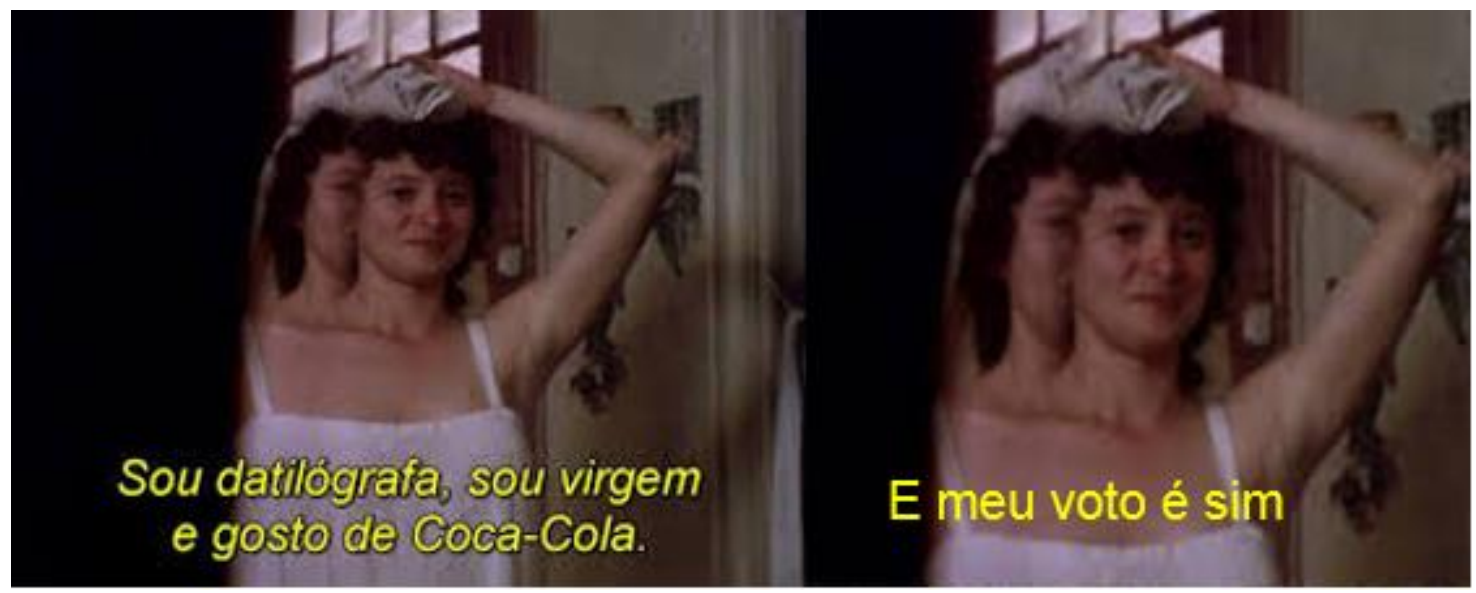

Nota-se que as estudantes optaram por utilizar como imagem a versão fílmica do romance, o que acaba prejudicando a interpretação sobre a figura da personagem, mas como não houve nenhum tipo de instrução que proibisse isso, não se leva como uma questão negativa. Macabéa chama a atenção, em geral, pelo sofrimento e grosseria a que é exposta, diante da ingenuidade que apresenta diante da vida. Algumas caracterizações realizadas pelo narrador também colaboram na tarefa de entendê-la como uma figura peculiar. Percebese como as frases utilizadas pelas alunas não correspondem a nenhum trecho do romance, mas fazem menção a um discurso que estava bastante em destaque 


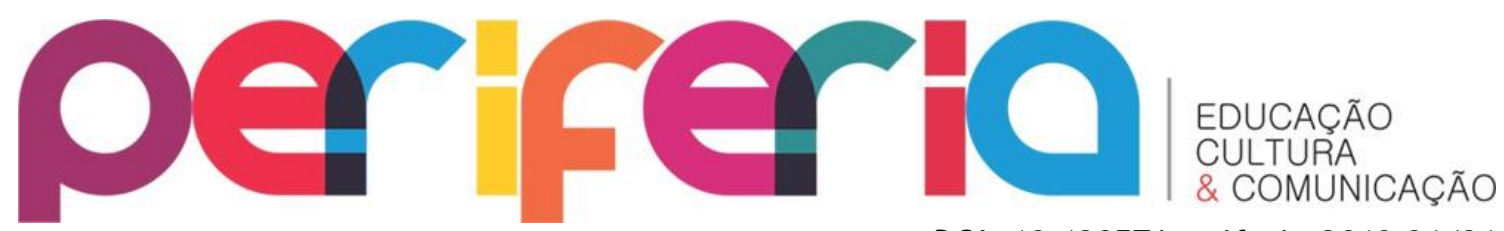

DOI: $10.12957 /$ periferia.2019.36436

no ano de 2016: a votação dos deputados federais diante da proposta de impeachment da presidenta Dilma Roussef.

Como é de conhecimento geral, muitas das justificativas de voto apresentadas na ocasião não tinham relação direta com o assunto em discussão, e culminaram em momentos de extremo constrangimento para muitos dos que acompanharam a votação. As estudantes, cientes dos efeitos diversos que aquelas falas criaram, acharam que as características de Macabéa também poderiam causar estranhamento e então lançaram mão dessa estratégia. Vemos, desse modo, a concretização da importância do contexto social para o leitor, o que é detalhado de forma importante por Rildo Cossoni, o que justifica a longa citação:

A interpretação depende, assim, do que escreveu o autor, do que leu o leitor e das convenções que regulam a leitura em uma determinada sociedade. Interpretar é dialogar com o texto tendo como limite o contexto. Esse contexto é de mão dupla: tanto é aquele dado pelo texto quanto o dado pelo leitor; um e outro precisam convergir para que a leitura adquira sentido. Essa convergência dá-se pelas referências à cultura na qual se localizam o autor e o leitor, assim como por força das constrições que a comunidade do leitor impõe ao ato de ler. 0 contexto é, pois, simultaneamente aquilo que está no texto, que vem com ele, e aquilo que uma comunidade de leitores julga como próprio da leitura (COSSON, 2012, p.41).

A importância do contexto, muitas vezes uma questão delicada de ser abordada em sala de aula, se mostra marcante no meme em questão, já que houve uma referência a um fato da cultura presente, culminando numa proposta de interpretação que é justamente o que chama atenção e pode garantir o sucesso da produção.

Vejamos a segunda produção, referente a $O$ Alienista, de Machado de Assis. É interessante notar como os estudantes acabam gostando desse conto/novela diante das possibilidades de discussão e entendimento do que significa "ser louco". O enredo conta a experiência de um médico que, após formar-se no exterior, volta à cidade de Itaguaí e resolve colocar em prática suas ideias sobre a cura para a loucura. Conceitos como cientificismo, visão da sociedade acerca dos comportamentos dos outros e relações sociais, além dos aspectos de teoria literária analisados no texto balizaram o conteúdo prévio à 


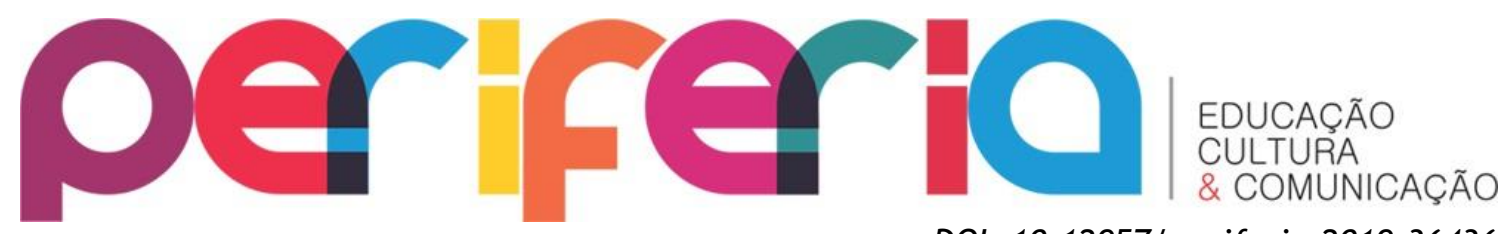

DOI: $10.12957 /$ periferia.2019.36436 produção dos memes. Até mesmo a música "Balada de louco", do grupo Mutantes, foi ouvida em sala para contextualização da discussão.

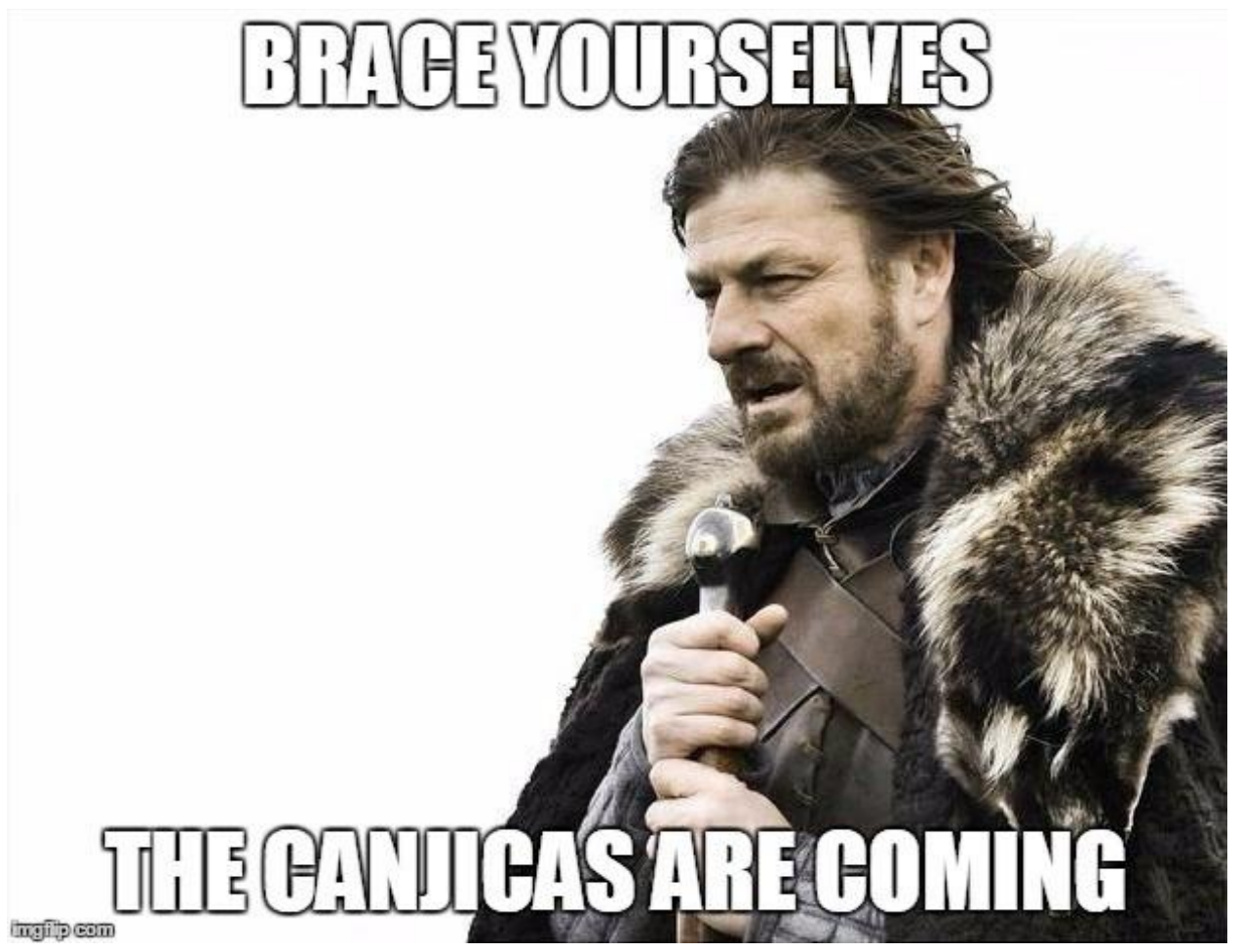

Novamente tendo como contexto um elemento social de grande sucesso à época, os estudantes, desta vez do segundo ano do curso técnico em Informática para Internet, fizeram uma intertextualidade com a já famosa frase da série Game Of Thrones, "The winter is coming". O enredo da obra televisiva retrata, em suma, um cenário político em torno de Sete Reinos, e o enunciado funciona, para alguns dos espectadores, como um sinônimo de que tempos difíceis estão para chegar, considerando que se trata do primeiro episódio da série e, que, portanto, é o prelúdio para todos os desdobramentos que a sustentarão. Os estudantes, então, parecem ter relacionado a expectativa de uma situação delicada com o que significaria uma revolta em torno das ações do alienista.

Jean Foucambert, em Modos de ser leitor (2008), define o ato de ler, ao pontuar que se escolhe o que pretende ler quando se depara com um texto. Também comenta sobre o que ele chama de terrorismo intelectual, ou seja, "obrigar" alguém a ler e considerar que aquilo é superior. Aqui, naturalmente, 


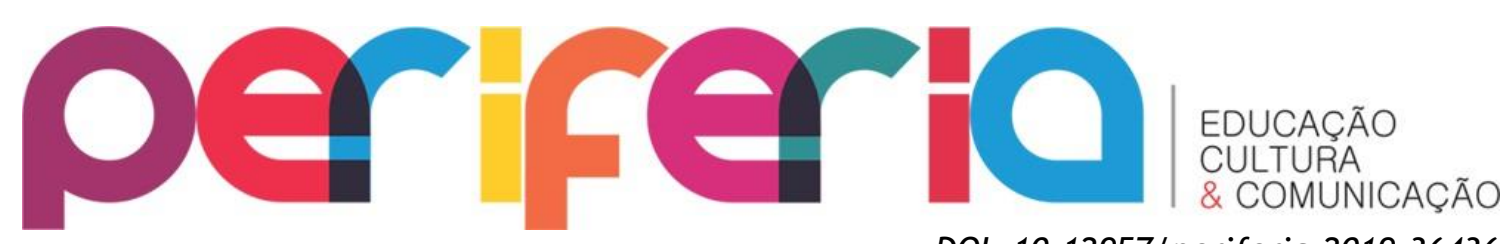

DOI: $10.12957 /$ periferia.2019.36436 temos a imagem trabalhando em conjunto, mas nos parece aplicável refletir acerca do que menciona o teórico:

Ler é, então, antes mesmo de procurar informação, ter escolhido a informação que se procura.[...] Ler, [...] trata-se sempre de uma atividade que encontra sua significação porque está inscrita no interior de um projeto. Pode-se discutir o valor do projeto, mas isto posto, a leitura é uma: trata-se sempre de tomar as informações que escolhemos tomar. (2008, p.63)

Isso se aplica quando pensamos na escolha desses estudantes de refletirem especificamente sobre o episódio da Revolta dos Canjicas, quando o barbeiro e grande parte da população, assustados com as ações e prisões pelos mais diversos motivos, resolve partir para um protesto que culminaria na "destituição" do governo, que havia criado até mesmo um imposto para colaborar com os custos da casa onde os loucos eram presos, e do médico. Naturalmente que a essência da obra machadiana permite análises das mais diversas, mas a possível estranheza na escolha desse episódio pode se explicar justamente pelas falas do professor Foucambert. Como professores, tentamos mediar a leitura do texto literário, e muitas vezes esquecemos que o adolescente a nossa frente vai fazer as escolhas dele de leitura, que, fatalmente, serão diferentes das que buscamos. A antecipação da opção deles atrapalha o trabalho e pode causar frustração, ao passo que respeitar a individualidade dessa escolha, calcada pela interação dele com o contexto a sua volta, e, vejamos o quão rico é este processo, como ele vai conseguir fazer com o que leitor da atividade proposta o acompanhe nessa leitura é o que expõe a validade da atividade com memes.

Diante disso, nos parece válido relembrar a colocação de Rildo Cosson (2012, p.39) a esse respeito: "Ler depende mais do leitor do que do texto. É o leitor que elabora e testa hipóteses sobre o que está no texto. É ele que cria estratégias para dizer o texto com base naquilo que já sabe sobre o texto e o mundo". Justamente por conta disso é que surgiram as possíveis dúvidas de interpretação também por parte da professora, já que as escolhas do leitor, no caso com idade e vivências diferentes, não são compatíveis com as utilizadas no momento de produção. 


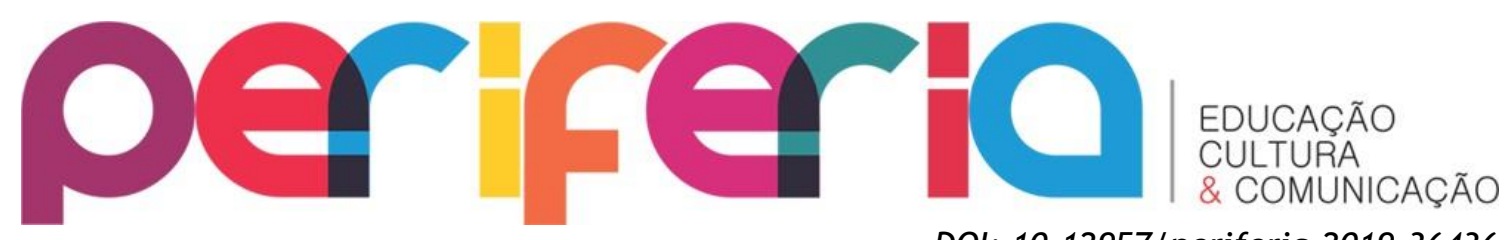

DOI: $10.12957 /$ periferia.2019.36436

Isso permite aos estudantes passarem do papel de leitores para produtores de texto, o que só tem a promover ganhos para a organização do processo de escrita deles. Vemos, mais uma vez, a validade de se trabalhar essa atividade para o trabalho com a língua materna.

\section{CONSIDERAÇÕES FINAIS}

Este momento de reflexão sobre a aplicação de uma atividade em sala de aula pode servir como inspiração para futuros trabalhos que criam, inclusive, a possibilidade de melhorar a abordagem aqui apresentada. Acima de tudo, é importante que tenhamos espaço para discussão a esse respeito, considerando que

Se queremos modificar os resultados do ensino da leitura [...] é necessário[...] que sua aprendizagem tenha relações diferentes com os outros elementos do sistema educativo. Ler, em 1980, para todos os indivíduos, não é a mesma coisa que ler, em 1880, para dez por cento do corpo social; e não é nem possível nem desejável tentar levar todos a atingirem um modo de leitura definido por alguns, cem anos antes. (FOUCAMBERT, 2008, p.154).

É preciso que respeitemos o ato de ler, obviamente, sem que ele fique em segundo plano, mas temos de nos atentar para a mudança dos processos de ensino e do público, entendendo que temos à disposição outros tipos de ferramentas que podem colaborar para a efetivação da cultura da leitura em âmbito escolar, desafio constante no cotidiano escolar.

0 trabalho com os memes permitiu que se verificasse, por fim, uma apropriação do sentido e das diversas possibilidades de se abordar um fato que pode soar aparentemente sem importância no enredo, mas que, fazendo parte da literatura, permite reflexões sobre o processo de formação humana propiciado por essa tarefa, potencializada pela escola, espaço de que se espera tal experiência. 


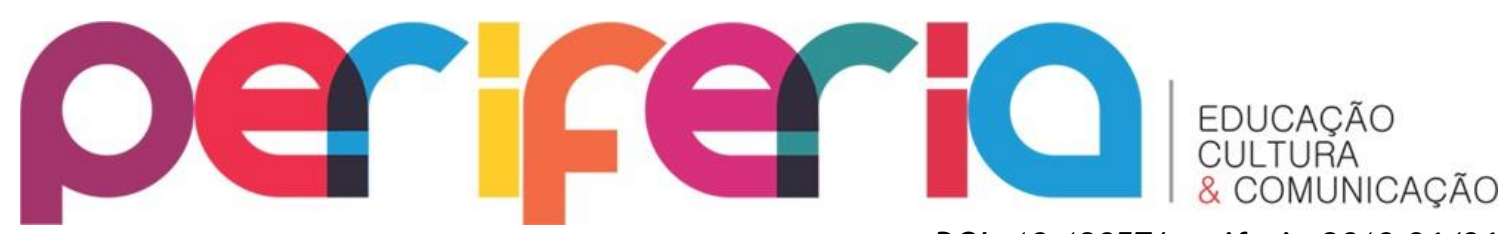

\section{REFERÊNCIAS}

BAKHTIN, Mikhail. Estética da criação verbal . Tradução de Maria Emsantina Galvão G. Pereira. 2 ed .São Paulo: Martins Fontes, 1997.

COSSON, Rildo. Letramento literário: teoria e prática. São Paulo: Editora Contexto, 2012.

COSTA, Rosimeri Claudiano da Costa; VILAÇA, Márcio Luiz Corrêa. O uso da rede social Facebook no ensino de língua portuguesa. In: Revista Philologus, Ano 19, N 57 - Supl.: Anais da VIII JNLFLP. Rio de Janeiro: CiFEFiL, set./dez.2013. Disponível em:

http://www.filologia.org.br/revista/57supl/79.pdf. Acesso em 10 jun. 2018.

DA SILVA, Ananias Agostinho. Memes virtuais: gênero do discurso, dialogismo, polifonia e heterogeneidade enunciativa. Revista Travessias. V.10, n.03, 28 ed, 2016. Disponível em: http://e-

revista.unioeste.br/index.php/travessias/article/view/15111. Acesso em 21 maio, 2018.

FOUCAMBERT, Jean. Modos de ser leitor: Aprendizagem e ensino da leitura no ensino fundamental. Tradução de Lucia P. Cherem e Suzete P.Bornatto.

Curitiba: Editora UFPR, 2008.

MINHOTO, Paula; MEIRINHOS, Manuel. As redes sociais na promoção da aprendizagem colaborativa: um estudo no ensino secundário. Educação, Formação \& Tecnologias, 4(2), 25-34 [Online], 2011. Disponível em:

http://eft.educom.pt/index.php/eft/article/view/227/0. Acesso em: 20 mar. 2018.

PINA, Gloria Rodriguez. A professora que pediu a suas alunas 'memes' de 'Cem Anos de Solidão'. El País, 19 jun.2016. Disponível em:

https://brasil.elpais.com/brasil/2016/06/18/cultura/1466244071_638548.htm l?id_externo_rsoc=FB_CM. Acesso em 30 maio. 2018. 